\title{
A post-fire management model to improve Aleppo pine forest resilience
}

\author{
D. Moya ${ }^{1}$, J. De las Heras ${ }^{1}$, F. R. López-Serrano ${ }^{1} \&$ V. Leone ${ }^{2}$ \\ ${ }^{1}$ Escuela Técnica Superior de Ingenieros Agrónomos de Albacete, \\ Universidad de Castilla-La Mancha, Spain \\ ${ }^{2}$ Dipartimento di Scienze dei Sistema Colturali, \\ Forestali e dell'Ambiente, Universita della Basilicata, Italy
}

\begin{abstract}
The number of forest fires, their severity and recurrence, the surface burned and the duration of fire risk season have increased in the Mediterranean basin over the last few decades. These factors promoted an increase of naturally regenerated, unmanaged pine forests and as a consequence, the risk of new wildfires. Aleppo pine (Pinus halepensis mill.) is an obligate seeder adapted to fire-prone habitats, and a very important timber species affected by this phenomenon. In eastern Spain alone more than 100000 ha of Aleppo pine forests were burned in summer, 1994. One of the forests (naturally regenerated) was selected in order to design an adequate post-fire management model.

Several plots were set in two different sites of the fires considered. Silvicultural treatments were carried out at five and ten years after the fire. All trees in the selected plots were marked and monitored. Growth, reproductive characteristics and several allometric parameters were measured in the treated plots. Several measurements in burned (all treated and control plots) and unburned plots were recorded in order to obtain structural patterns and biodiversity indices,

The plots thinned ten years after the fire and the unburned plots showed a regular, non-aggregated distribution pattern and low diameter differentiation. Also, these thinned plots showed biodiversity characteristics similar to mature stands. The increases and final values for growth and reproductive characteristics measured in the monitored plots were different for each site but thinning improved growth and the amount of seeds stored in the canopy, thus insuring a more successful regeneration should fire affect the same site again in the early life stages.

The optimal management policy obtained improves growth and reproductive processes, shortens the juvenile phase, accelerates the mature age and increases the canopy seed bank. It reduces the immaturity risk and improves the post-fire resilience.
\end{abstract}

Keywords: thinning, pruning, biodiversity, immaturity risk, canopy seed bank. 


\section{Introduction}

Deficient forest management and global warming have increased the number, severity and recurrence of wildfires in the Mediterranean area [7]. Pinus halepensis Mill. (Aleppo pine) is the most important and widely diffused tree species (broad geographic extension and adaptive strategies to fire-prone habitats) in low elevation areas around the Basin. Usually, Aleppo pine stands are poorly managed and post-fire, naturally regenerated stands are increasing in area [11]. Fire-resilience is based on early and abundant cone production and large seed storage in the grey and closed (serotinous) cones [8, 13]. After a fire, the Aleppo pine community returns to its initial floristic composition [14] but high fire recurrence can interrupt vegetative succession.

Several studies confirm that growth, reproductive strategies, spatial patterns and biodiversity could be improved modifying inter- and intra-specific competition [8-10]. Silvicultural treatments (mainly pruning and thinning) in young, naturally regenerated stands have been confirmed to be useful post-fire management tools but they have to be adapted depending on the main objective of forest policy $[3,8,9,15]$. There is currently a lack of knowledge regarding optimal management depending on forest characteristics and policies.

Within the framework of this goal, our study aims to assess optimal management in young Aleppo pine stands to: 1) improve growth and reduce the immaturity risk, 2) shorten the period to reach similar structural patterns and plant diversity than those observed in mature Aleppo pine stands and 3) increase fire-resilience to ensure natural regeneration after a new fire event.

\section{Materials and methods}

\subsection{Study site}

In SE Spain, about 14000 ha in Yeste (YES, Province of Albacete: $2^{\circ} 20^{\prime} \mathrm{W} 38^{\circ}$ $20^{\prime} \mathrm{N} ; 1010 \mathrm{~m}$ amsl) were burned in the summer of 1994 . The soil was mainly carbonate substratum with a $\mathrm{pH}$ value of about 8.5 and low slope $(<5 \%)$. The mean annual rainfall and temperature for the last thirty years were 498,00 mm and $15.03{ }^{\circ} \mathrm{C}$ in YES (Dry ombroclimate). The area naturally regenerated after the fire but seedling density varied from about 7000 to 30000 pine trees $\mathrm{ha}^{-1}[3$, 8]. The burned pine trees were cut and removed. The remaining dead wood was piled up in lines to prevent soil dragging.

\subsection{Forest management}

In July, 1999, we designed the experimental plots and carried out several silvicultural treatments. Pruning and two early thinning intensities were applied (reducing the final pine tree density to 1600 trees ha $^{-1}$ and to 800 trees ha ${ }^{-1}$ ). The plots were treated five years after the fire (1999), ten years after the fire (2004) and at different ages. Every treatment was carried out in three plots in each site. Also, three plots were set in the unburned areas during the last 70 years (UB) and 
three in each unmanaged burned site as control plots (C). Plot shape was rectangular $\left(10 \times 15 \mathrm{~m}^{2}\right)$ and in order to prevent edge effect, we established a corridor between plots ( $6 \mathrm{~m}$ wide).

The treatments carried out were the following:

- C: control (no treatments).

- T: high intensity thinning carried out in 1999 to a final density of 1600 trees ha $^{-1}$.

- $\quad$ P: pruning in 1999.

- t: very high intensity thinning carried out in 1999 to a final density of 800 trees ha ${ }^{-1}$.

- $\quad$ T+P: high intensity thinning and pruning carried out in 1999 .

- T04: high intensity thinning carried out in 2004 to a final density of 1600 trees $\mathrm{ha}^{-1}$.

- t04: very high intensity thinning carried out in 2004 to a final density of 800 trees ha $\mathrm{a}^{-1}$.

- t04+p04: very high intensity thinning plus pruning, both in 2004.

- T+P04: high intensity thinning carried out in 1999 and pruning in 2004.

- T04+P04: high intensity thinning plus pruning both carried out in 2004.

- $\mathrm{T}+\mathrm{t} 04+\mathrm{P} 04$ : high intensity thinning in 1999 and very high intensity of thinning plus pruning, both in 2004 .

\subsection{Measurements}

In the plots, the height and trunk diameter $(30 \mathrm{~cm}$ above the soil) of all pine trees were measured. Five pine trees [12] were randomly selected to measure the distance to the four nearest neighbor-pine trees and the angle between consecutive neighbors (higher or lower than $90^{\circ}$ ). The Clark-Evans index (CE, [2]), the Byth-Ripley index (BR, [1]) and the differentiation diameter (DD) were calculated. Plant diversity was measured with the following indices [6]: shrub richness, total average cover (TAC) and Shannon index $(\mathrm{H})$. In order to characterize the cone crop, all cones found in the pine trees were classified (according to their age) and recorded in spring, 2007. The first reproductive year (age when a pine tree begins to bear cones) was estimated by counting the whorls over the oldest cone [15]. Therefore, the number of cone-bearing trees (reproductive trees) was recorded to characterize the reproductive stages (juvenile and reproductive phase). The canopy seed bank assessment was defined as the number of sound and germinal seeds per hectare contained in the mature and serotinous cones in the current year [4]. It was defined as the product of the average number of cones per hectare and the average number of sound and germinal seeds per cone. These values were obtained from seed samples submitted to a cutting test and germination test [8]. The data were recorded from 1999 to 2007.

To obtain the optimal management policy the different treatments were averaged and listed. The treated plots were ordered and selected according to the model in six steps:

1. Non-decreasing height-diameter relationship.

2. Earliest reproductive age. 
3. Reproductive phase reached ( $>50 \%$ reproductive trees).

4. High mature and serotinous cone crop.

5. Spatial patterns and plant diversity similar to mature areas.

6. Canopy seed bank enough to ensure natural regeneration after fire. The model steps have been summarized and clarified in Figure 1.

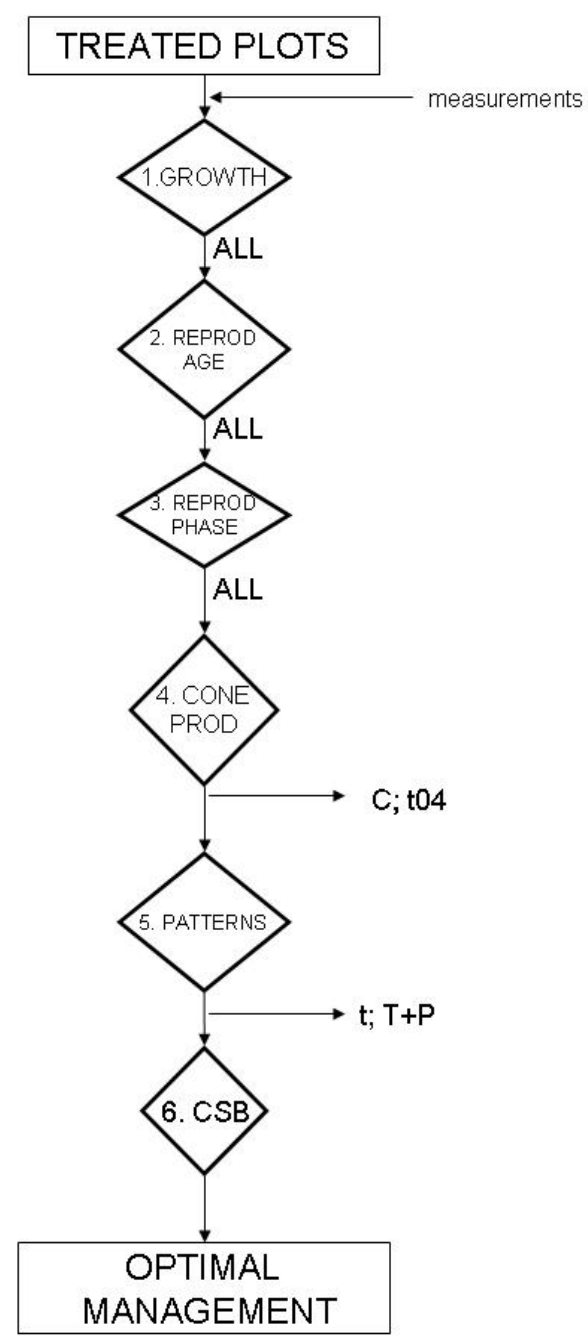

Figure 1: $\quad$ Steps included in the model. Optimal management was selecting treatments that reached all objectives. 


\subsection{Statistical analysis}

The relationship between cone volume and the number of seeds contained was obtained with a simple linear regression in order to obtain the relationship between them. Multifactor ANOVA and General Linear Model (GLM) were applied to obtain relations between the studied factors. A Tukey test (High Significant Difference) was used to check significant differences between silvicultural treatments. The Kruskal-Wallis test was used to check median significant differences between independent variables. The values were $\sqrt{\text { arcsine }}$ or log transformed to achieve normality assumptions and homoscedasticity but they were shown without transformation, with standard error included $( \pm$ SE). All statistical analyses were conducted using a critical $p$-value of $\leq 0.05$.

\section{Results}

\subsection{Growth: height-diameter relationship}

The height-diameter relationship showed a constant slope in the linear regressions obtained for each treatment. The slopes were not significantly different and were averaged to the linear regression: $\log (\mathrm{H})=4.4+0.55 * \log (\mathrm{D})$.

\subsection{First reproductive age}

The earliest reproductive age was found in T04 plots (five years after the fire) and the latest was in $\mathrm{T}+\mathrm{P}$ and $\mathrm{T}^{\prime} \mathrm{t} 04+\mathrm{p} 04$, but no significant differences were found. The sixth year after the fire at least one tree in each plot had produced cones. Therefore, all plots moved up to the next step of the model.

\subsection{Reproductive phase}

The number of reproductive trees was high in all the study plots in 2007. Several plots reached the reproductive phase before the tenth year after the fire $(\mathrm{T}+\mathrm{t} 04+\mathrm{p} 04, \mathrm{t}, \mathrm{T}+\mathrm{p} 04$ and $\mathrm{t} 04+\mathrm{p} 04)$. The other plots did so before the thirteenth year after a fire (T+P, C, T04+p04, T, T04 and t04), so no differences were found for young Aleppo pine plots and all plots were transferred to the next step.

\subsection{Cone production}

Four different groups were obtained by comparing average values. The $\mathrm{T}+\mathrm{p} 04$ plots showed the highest cone production (46399.97 \pm 5304.39 cones/ha) and the lowest group was made up of C $(9666.65 \pm 543.41)$ and $t 04(8000.00 \pm 1918.06)$ plots. Both treatments were removed from the model (Figure 2).

\subsection{Spatial patterns and plant diversity}

The spatial pattern indices showed a tendency towards a regular distribution (CE values similar to unit) with spatial dependency (low BR values, no significant differences) in thinned and unburned plots. Significant differences were found 
for $\mathrm{t}$ plots showing higher clustered distribution. The significantly highest shrub richness was recorded in $\mathrm{T}+\mathrm{P} 04$ and $\mathrm{t} 04+\mathrm{P} 04$ plots but $\mathrm{TAC}$ and $\mathrm{H}$ presented no significant differences. From this point onward we discarded $t$ and $\mathrm{T}+\mathrm{P}$ treatments (Table 1).

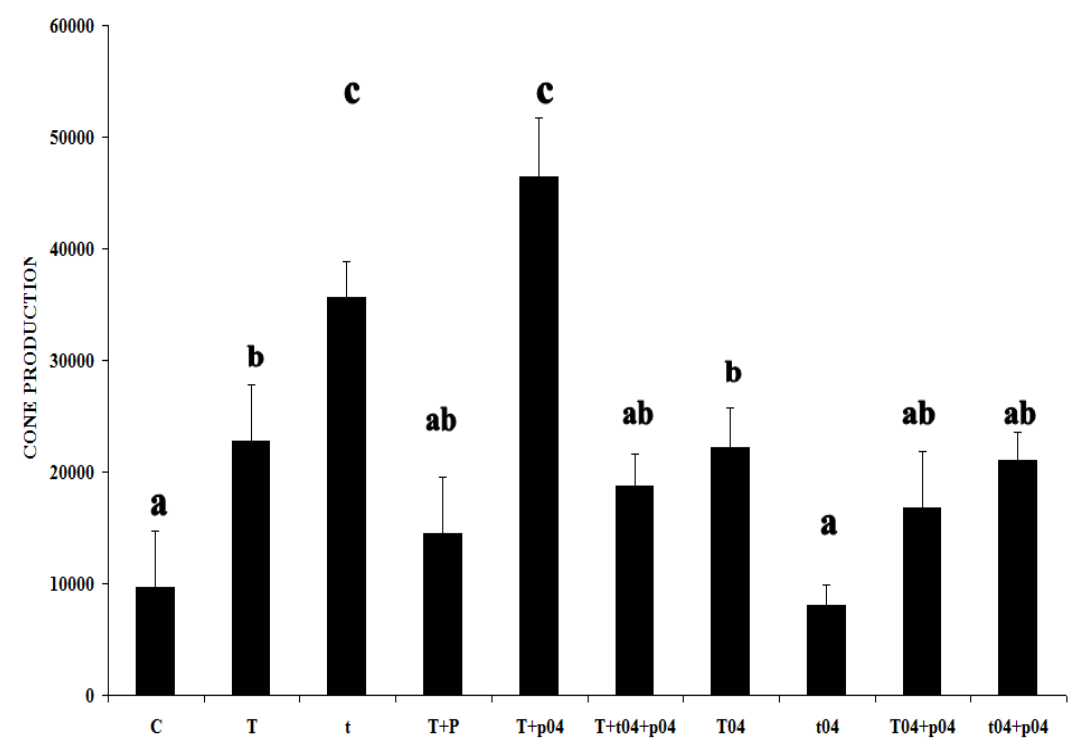

Figure 2: Cone production (mature and serotinous cones per hectare). Columns with different small letters represent significant differences among burned plots using Tukey test at $p<0.05$.

\subsection{Canopy seed bank}

The highest amount of sound and germinated seeds stored in the mature and serotinous cones in 2007 was found in $\mathrm{t}, \mathrm{T}+\mathrm{p} 04$ and $\mathrm{t} 04+\mathrm{p} 04$ plots. According to the values of seedling mortality [5] and germination success after dispersion [6], the value for possible natural regeneration (NR) was:

$\mathrm{NR}_{\text {Optimist scenario }}=(0.5 * \mathrm{CSB}) * 0.09$

$\mathrm{NR}_{\text {Pessimistic scenario }}=(0.8 * \mathrm{CSB}) * 0.12$

\section{Discussion}

Studies have proven that growth, cone production and nutrient allocation in young Aleppo pine stands are influenced by tree density [3, 8]. Also, low tree density can promote a higher amount of seeds stored in the mature and serotinous cones in the pine tree canopy [3, 7, 12]. Hence, silvicultural treatments affecting tree density could improve growth, biodiversity and reproductive parameters $[3,14]$ but optimal management designed to be flexible 
Table 1: $\quad$ Spatial pattern indices showed that $\mathrm{t}$ and $\mathrm{T}+\mathrm{P}$ plots had to be excluded from the model.

\begin{tabular}{|c|c|c|c|}
\hline Treatment & $C E$ & $B R$ & $D D$ \\
\hline $\mathrm{T}+\mathrm{P} 04$ & $0.89 \pm 0.23^{a b}$ & $0.49 \pm 0.11^{\mathrm{a}}$ & $0.67 \pm 0.11^{\mathrm{ab}}$ \\
\hline T04 & $1.01 \pm 0.12^{\mathrm{ab}}$ & $0.35 \pm 0.03^{\mathrm{a}}$ & $0.67 \pm 0.06^{\mathrm{ab}}$ \\
\hline $\mathrm{T}+\mathrm{P}$ & $0.88 \pm 0.17^{\mathrm{ab}}$ & $0.45 \pm 0.06^{\mathrm{a}}$ & $0.75 \pm 0.07^{\mathrm{b}}$ \\
\hline $\mathrm{C}$ & $0.68 \pm 0.39^{a}$ & $0.46 \pm 0.28^{\mathrm{a}}$ & $0.72 \pm 0.09^{\mathrm{b}}$ \\
\hline $\mathrm{T}+\mathrm{t} 04+\mathrm{P} 04$ & $1.05 \pm 0.26^{\mathrm{ab}}$ & $0.26 \pm 0.06^{\mathrm{a}}$ & $0.52 \pm 0.10^{\mathrm{a}}$ \\
\hline $\mathrm{T}$ & $0.97 \pm 0.16^{\mathrm{ab}}$ & $0.45 \pm 0.11^{\mathrm{a}}$ & $0.75 \pm 0.10^{\mathrm{b}}$ \\
\hline t04 & $0.82 \pm 0.01^{\mathrm{ab}}$ & $0.47 \pm 0.03^{\mathrm{a}}$ & $0.58 \pm 0.03^{\mathrm{ab}}$ \\
\hline T04+P04 & $1.18 \pm 0.30^{b}$ & $0.45 \pm 0.20^{\mathrm{a}}$ & $0.67 \pm 0.10^{\mathrm{ab}}$ \\
\hline $\mathrm{t} 04+\mathrm{P} 04$ & $1.12 \pm 0.09^{\mathrm{ab}}$ & $0.29 \pm 0.07^{\mathrm{a}}$ & $0.50 \pm 0.04^{\mathrm{a}}$ \\
\hline $\mathrm{t}$ & $1.11 \pm 0.26^{b}$ & $0.26 \pm 0.06^{\mathrm{a}}$ & $0.66 \pm 0.16^{\mathrm{ab}}$ \\
\hline UB & $0.80 \pm 0.18^{a b}$ & $0.48 \pm 0.10^{\mathrm{a}}$ & - \\
\hline
\end{tabular}

for a variety of concurrent objectives have to be developed. According to our model for a very dry inland area, the first objective (first to fourth steps of the model, i.e. growth increase and risk immaturity prevention) was reached in all plots with the exception of untreated plots and plots recently thinned (to the lowest density). The conclusion is that the silvicultural treatments are improving health and reproductive characteristics in this stand although a drastic drop in pine tree density could require more time to respond to the treatment. The time needed to reach similar a spatial pattern and plant diversity was lower than 13 years in almost all plots; $\mathrm{t}$ and $\mathrm{T}+\mathrm{P}$ plots did not reach the values found in the mature stands. This could be due to the negative effects of pruning when the stands were five years old [3] and the short time given to the plants to regenerate in the intensely thinned plots, causing their failure to reach the second objective (i.e similar structure and plant diversity as mature stands). Finally, a sufficient 
amount of seeds stored in order to insure natural regeneration was reached in t04+P04, T+p04 and t, but the latter did not comply with the third objective (i.e. fire-resilience increase).

\section{Conclusion}

The optimal management policy to reach the three main objectives for forest health, plant diversity and resilience to fire were:

a) Early thinning to a final pine tree density of 1600 trees/ha five years after the fire, completing the treatment with pruning ten years after the fire.

b) Pruning and thinning to a final pine tree density of 800 trees/ha ten years after the fire.

These simple and inexpensive silvicultural models shape the juvenile stands regenerated after fires, giving them abundant and early fertile seed production, thus fostering species resilience. For the study area this seems to avoid fires returning to the same area with high frequency, which could definitely eliminate the presence of these pine stands that are naturally abundant in the Mediterranean Basin.

\section{References}

[1] Byth K, Ripley BD. On sampling patterns by distance methods. Biom 36: 279-284. 1980

[2] Clark PJ, Evans FC. Distance to nearest neighbour as a measure of spatial relationships in populations. Ecol 35: 445-453. 1954

[3] González-Ochoa AI, López-Serrano FR, de las Heras J. Does post-fire forest management increase tree growth and cone production in Pinus halepensis? For Ecol Manag 188: 235-247. 2004

[4] Goubitz, S., Nathan, R., Roitemberg, R., Shmida, A., Ne’eman, G. Canopy seed bank structure in relation to: fire, tree size and density. Plant Ecology 173, 191-201. 2004.

[5] Herranz, J.M., Martinez-Sanchez, J.J., Marin, A., Ferrandis, P. 1997. Postfire regeneration of Pinus halepensis Mill. in a semi-arid area in Albacete province (southeastern Spain). Ecoscience 4: 86-90.

[6] Izhaki I., and Ne'eman, G. 2000. Soil seed banks in Mediterranean pine forests, in: Ne'eman, G. and Trabaud, L. (eds.), Ecology, Biogeography and Management of Pinus halepensis and P. brutia forest ecosystems in the Mediterranean Basin. Backhuys publishers, Leiden, pp: 167-181.

[7] Magurran, AE. Ecological Diversity and its Measurement. Princeton University Press, Princeton. 1988

[8] Moriondo M, Good P, Durao R, Bindi M, Giannakopoulos C, Corte-Real C. Potential impact of climate change on fire risk in the Mediterranean area. Clim Res 31:85-95. 2006 
[9] Moya D, De las Heras J, Lopez-Serrano FR, Leone V. Optimal intensity and age of management in young Aleppo pine stands for post-fire resilience. For Ecol Manag 255: 3270-3280. 2008

[10] Moya D, Espelta JM, Lopez-Serrano FR, Eugenio M, De las Heras J. Natural post-fire dynamics and serotiny in ten year-old Pinus halepensis Mill. stands along a geographic gradient. Int J of Wildland fire 17: 287292. 2008

[11] Moya D, Saracino A, Salvatore R, Lovreglio R, De las Heras J, Leone V. Anatomic basis and insulation of serotinous cones in Pinus halepensis Mill. Trees Struct and Func. DOI 10.1007/s00468-008-0211-1. 2008

[12] Nathan, R., Ne'eman, G. Spatiotemporal dynamics of recruitment in Aleppo pine (Pinus halepensis Mill). Plant Ecology 171, 123-137. 2004.

[13] Pommerening A. Evaluating structural indices by reversing forest structural analysis. For Ecol and Manag 224: 266-277. 2006

[14] Tapias R, Gil L, Fuentes-Utrilla P, Pardos JA. Canopy seed banks in Mediterranean pines of south-eastern Spain: a comparison between Pinus halepensis Mill., P. pinaster Ait., P. nigra Arn. and P. pinea L. J Ecol 89: 629-638. 2001

[15] Verroios G, Georgiadis T. Post-fire vegetation succession: the case of Aleppo Pine (Pinus halepensis Miller) forests of Northern Achaia (Greece). Fresenius Environ Bull 11(4): 186-193. 2002

[16] Verkaik, I., Espelta, J.M. Post-fire regeneration thinning, cone production, serotiny and regeneration age in Pinus halepensis. Forest Ecology and Management 231, 155-163. 2006 